\title{
Changes in in vitro Rumen Fermentation Characteristics of Different Compositions of Total Mixed Rations (TMR) and the Ensiled TMRs
}

\section{Wang Chao $^{1 \dagger}$,Yutaka Uyeno ${ }^{2 *}$, Anuraga Jayanegara ${ }^{3}$, Makoto Kondo ${ }^{1}$, Tomomi Ban-Tokuda ${ }^{1}$, Hiroki MATSUI ${ }^{1}$}

\author{
${ }^{1}$ Graduate School of Bioresources, Mie University, Kurimamachiya, Tsu City, Mie 514-8507, Japan; ${ }^{2}$ Faculty of \\ Agriculture, Shinshu University, Minamiminowa, Nagano 399-4598, Japan; ${ }^{3}$ Faculty of Animal Science, Bogor \\ Agricultural University, Bogor 16680, Indonesia.
}

\begin{abstract}
To evaluate the effects of the composition of total mixed rations (TMR) and ensiling of the TMR on rumen fermentation properties and methane production, we compared two types of TMRs, which were optimized for dairy cattle and beef cattle, and their ensiled TMRs (eTMR). To make eTMRs, TMRs were wrapped and fermented for 40 days. These eTMRs and TMRs were used for in vitro ruminal incubation experiment. The type of TMR and ensiling both affected total short chain fatty acids, the amount of methane production, and relative proportions of acetate and butyrate in the in vitro rumen cultures of tested TMRs. The relative abundance methanogenic archaea in respective cultures determined by quantifying a gene involved in methane production ( $m c r A$ : $\alpha$-subunit of methyl co-enzyme $\mathrm{M}$ reductase) was also affected by both the type and the ensiling, which was higher in the eTMRs than the TMRs $(p<0.001)$. The results of the present study suggest that not only ensiling TMR but also the composition of TMR may affect in vitro rumen fermentation patterns, and that changes in the degree of methane generation due to ensiling TMR may also depend on the fermentation kinetics.
\end{abstract}

Keywords | Ensiled TMR, Dietary carbohydrates, Methanogen, Short chain fatty acids

Editor | Kuldeep Dhama, Indian Veterinary Research Institute, Uttar Pradesh, India.

Received | October 29, 2015; Revised | November 10, 2015; Accepted | November 12, 2015; Published | April 09, 2016

*Correspondence | Yutaka Uyeno, Faculty of Agriculture, Shinshu University, Minamiminowa 8304, Nagano, Japan; Email: ytkuyeno@shinshu-u.ac.jp

$\dagger$ Present address | Institute of Animal Nutrition and Feed Research, Inner Mongolia Academy of Agricultural and Animal Husbandry Sciences, Hohhot 010031, Inner Mongolia, China.

Citation | Wang C, Uyeno Y, Jayanegara A, Kondo M, Ban-Tokuda T, Matsui H (2016). Changes in in vitro rumen fermentation characteristics of different compositions of total mixed rations (TMR) and the ensiled TMRs. Adv. Anim. Vet. Sci. 4(4): 178-182.

DOI | Http://dx.doi.org/10.14737/journal.aavs/2016/4.4.178.182

ISSN (Online) | 2307-8316; ISSN (Print) | 2309-3331

Copyright $(\subset) 2016$ Wang et al. This is an open access article distributed under the Creative Commons Attribution License, which permits unrestricted use, distribution, and reproduction in any medium, provided the original work is properly cited.

$\mathrm{T}$ otal mixed ration (TMR) has been widely applied to cattle feeding, but because of high nutrient and sufficient moisture, it needs to be addressed to overcome its immediate deterioration. The use of ensiled TMR (referred to as eTMR or TMR silage) has been expanded because of its long-term preservation and favourable nutritional changes due to lactic acid fermentation. Studies on eTMR have increased in recent years, particularly in Asian counties that are usually in humid climate (Nishino et al., 2004; Wang and Nishino, 2008; Weinberg et al., 2011). Recently, it was reported that eTMR using whole-crop rice and rice bran leads to low methane production in vitro and in vivo, compared to TMR which was not ensiled (Cao et al., 2010a; Cao et al., 2012), resulting in the decrease of feed energy loss. Methane production in ruminants has attracted a great deal of attention in relation to the consequential decrease in feed efficiency and to its contribution to the greenhouse gas effect and global warming (Eckard et al., 2010). In this regard feeding eTMR seems advantageous for reserving the energy to the body, however, the mechanism has been uncovered yet. Therefore, to determine whether the decrease in ruminal methane output by applying eTMR can be regarded as a common case, we conducted an in vitro ruminal culture experiment to evaluate nutritional changes and the ruminal fermentation nature of two types of commercial eTMR the rations of which were modified for dairy cattle and beef cattle (TMR-D and TMR-B, respectively). To evaluate whether methanogenic archaea were lower in response to decreases in the in vitro rumen methane production of eTMR compared to the TMR before ensiling, we also monitored the copy number of a gene involved in methanogenesis by the ar- 
chaea ( $m c r A$ : $\alpha$-subunit of methyl co-enzyme $\mathrm{M}$ reductase gene).

Tested TMR products were manufactured at a regional company in Japan. We obtained two types of TMRs whose rations were modified to meet different requirement between dairy cattle and beef cattle, and referred them to as TMR-D and TMR-B. TMR-D was composed of 45\% roughage, including corn silage, sorghum silage, and Italian ryegrass silage, and 55\% concentrates, including corn grain, barley grain, wheat bran, soybean meal, and corn gluten feed on a dry matter (DM) basis. TMR-B was composed of $20 \%$ rice straw silage and $80 \%$ concentrates on a DM basis. After mixing, subsamples were taken as TMR before ensiling and stored at $-30^{\circ} \mathrm{C}$ until use. For TMR ensiling, approximately $350 \mathrm{~kg}$ of TMR on a fresh matter (FM) basis was wrapped with stretch film using a baling machine. The fermentation period was 40 days for both eTMRs. The nutritional values and fermentation products were determined as described in our previous studies (Kondo et al., 2015).

We further applied these eTMRs and TMRs as tested material to in vitro ruminal incubation experiment. Incubation was performed as described in our previous paper (Kondo et al., 2015). Three ruminally cannulated crossbreed heifers (Holstein $\times$ Japanese Black cattle) were used. These animals were offered Italian ryegrass straw and commercial concentrate for 1:1 ratio. Rumen fluid samples were collected via cannula just prior to morning feeding. Collected rumen fluid from each animal was filtered through four layers of cheesecloth and pooled among the three animals at equal ratio. Subsequently strained rumen fluid was diluted (1:2) with pre-warmed McDougall buffer which had been flushed with $\mathrm{CO}_{2}$ gas to adjust $\mathrm{pH}$ at 6.8 . The $50 \mathrm{~mL}$ of the diluted rumen fluid was dispensed into $120-\mathrm{mL}$ serum bottles with substrate $(1.0 \mathrm{~g})$, followed by flushing with $\mathrm{CO}_{2}$ gas. Inoculated bottles ( $\mathrm{n}=3$ per group) were sealed with a butyl rubber stopper and aluminum cap, then incubated anaerobically for $24 \mathrm{~h}$ at $39^{\circ} \mathrm{C}$ with shaking at $180 \mathrm{rpm}$ in a water bath. After $24 \mathrm{~h}$ of incubation, all bottles were cooled on ice to stop fermentation and sampled to determine headspace gas composition, dry matter degradability, short-chain fatty acids (SCFAs), methane generation, and the gene $(m c r A)$. Analyses were conducted as described previously (Denman et al., 2007; Abrar et al., 2015). Real-time PCR for the quantification of $m c r A$ copy number was performed on a StepOnePlus Real-Time PCR Systems (Applied Biosystems, Foster City, CA USA). A primer set (qmcrA-f 5' - TTCGGTGGATCDCARAGRGC -3' and qmorA-r 5' - GBARGTCGWAWCCGTAGAATCC $-3^{\prime}$ ) was used for this assay. The purified DNA was used as template. The reaction mixture $(20 \mu \mathrm{L})$ contained $1.0 \mu \mathrm{L}$ DNA, $10.0 \mu \mathrm{L}$ Thunderbird ${ }^{\circledast}$ SYBR $^{\circledast}$ qPCR Mix, $0.3 \mu \mathrm{M}$ of each primer, $0.4 \mu \mathrm{L} 50 \times$ ROX. The assay was carried out under the following conditions: $1 \mathrm{cy}-$ cle of $95^{\circ} \mathrm{C}$ for $1 \mathrm{~min}, 40$ cycles at $95^{\circ} \mathrm{C}$ for $15 \mathrm{~s}, 60^{\circ} \mathrm{C}$ for 1 min. Standard DNA was prepared and used as previously described by Lwin et al. (2012). Measurements were analyzed by two-way analysis of variance (ANOVA) in which the two fixed factors were the type and ensiling, using SAS 9.3 (SAS Institute, Carry, USA). When significant ( $\mathrm{p}<$ 0.05 ) effects were detected, differences among means were determined using the post-hoc Tukey test. Data of methane production and $m c r A$ abundance from 12 samples were analyzed by pairwise correlations of variables.

Nutritional values and the fermentation data of TMRs were shown in Table 1. In both eTMRs, values of soluble sugar were significantly lower than the respective TMRs. This suggested that bacteria that contribute silage fermentation (e.g., Lactobacillus species) utilized these readily available carbohydrates to convert to lactate and acetate (Lima et al., 2010). In respect to neutral detergent fiber (NDF), increase and decrease trends of these values during ensiling were different between the two types, whereas this may have been in part due to the differences in nutritional value of the component materials depending on the timing of blending. Crude protein was higher in the eTMR than in the original TMR of both types. Furthermore, as we have reported (Kondo et al., 2015), soluble protein and $\mathrm{NH}_{3}$ were more prominent in the eTMR than in the TMR (data not shown). Collectively, these observations indicated that the nutritional aspects and fermentation characteristics of the eTMRs and the TMRs used in this study were within the normal ranges (Nishino et al., 2004; Kondo et al., 2015).

The results of the in vitro cultivation experiment are shown in Table 2. Dry matter disappearance (DMD) in the eTMR-B culture was higher than in the TMR-B culture, but the difference was marginal. In both eTMR cultures, total SCFA and acetate proportion were significantly higher than that of cultures of the original TMRs. Ensiling showed no effect on the propionate proportion, while the difference between type of TMR was significant. These data clearly indicated that not only the composition but also the presence or absence of the TMR ensiling process affected in vitro rumen fermentation characteristics. We assumed that characteristics of carbohydrate composition in the TMRs may primarily determine the fermentation patterns of the in vitro rumen culture. The complexity of the rumen microbial ecosystem supports the ability to efficiently convert various carbohydrates to SCFA for host energy via stepwise disposal of hydrogen through reduction of $\mathrm{CO}_{2}$ to methane (Morgavi et al., 2010). In the case of the TMR-Bs, for example, major substrates for carbohydrate digestion are regarded those that can be utilized easily according to the data in Table 1 . These substrates can be immediately digested by ruminal bacteria that are major 
Table 1: Nutrients and fermentation properties of tested TMRs and ensiled TMRs (eTMR)

\begin{tabular}{|c|c|c|c|c|c|c|c|c|}
\hline & \multicolumn{2}{|c|}{ TMR-D ${ }^{1)}$} & \multicolumn{2}{|c|}{ TMR-B ${ }^{1)}$} & \multirow[t]{2}{*}{ SEM } & \multicolumn{3}{|c|}{ p-value } \\
\hline & $\begin{array}{l}\text { TMR } \\
(\mathrm{n}=3)\end{array}$ & $\begin{array}{l}\text { eTMR } \\
(\mathrm{n}=3)\end{array}$ & $\begin{array}{l}\text { TMR } \\
(\mathrm{n}=3)\end{array}$ & $\begin{array}{l}\text { eTMR } \\
(\mathrm{n}=3)\end{array}$ & & Type & Ensiling & $\begin{array}{l}\text { Type } \times \\
\text { Ensiling }\end{array}$ \\
\hline Dry matter (\%) & 55.3 & 53.4 & 54.2 & 55.9 & 0.4 & 0.255 & 0.590 & 0.108 \\
\hline $\mathrm{pH}$ & $5.66^{\mathrm{a}}$ & $4.36^{\mathrm{b}}$ & $6.23^{c}$ & $4.13^{\mathrm{b}}$ & 0.26 & 0.069 & $<0.001$ & $<0.001$ \\
\hline Lactate (\% DM) & $1.84^{\mathrm{a}}$ & $8.80^{\mathrm{b}}$ & $0.27^{\mathrm{a}}$ & $7.63^{\mathrm{b}}$ & 1.12 & 0.065 & $<0.001$ & 0.811 \\
\hline Acetate (\% DM) & $1.08^{\mathrm{ab}}$ & $3.44^{\mathrm{c}}$ & $0.28^{\mathrm{a}}$ & $1.32^{\mathrm{b}}$ & 0.36 & $<0.001$ & $<0.001$ & 0.005 \\
\hline Propionate (\% DM) & $0.20^{\mathrm{ab}}$ & $0.24^{\mathrm{a}}$ & $0.00^{c}$ & $0.04^{\mathrm{bc}}$ & 0.04 & 0.001 & 0.387 & 0.936 \\
\hline Butyrate (\%DM) & 0.18 & 0.06 & 0.21 & 0.23 & 0.04 & 0.190 & 0.423 & 0.560 \\
\hline Total organic acids (\%DM) & $3.29^{a}$ & $12.54^{\mathrm{b}}$ & $0.77^{\mathrm{c}}$ & $9.22^{\mathrm{d}}$ & 1.43 & 0.008 & $<.0001$ & 0.578 \\
\hline Organic matter (\% DM) & 92.0 & 92.0 & 90.8 & 91.7 & 0.2 & 0.080 & 0.389 & 0.282 \\
\hline Crude protein (\% DM) & $14.0^{\mathrm{a}}$ & $15.6^{\mathrm{b}}$ & $10.3^{c}$ & $11.7^{\mathrm{d}}$ & 0.6 & $<0.001$ & 0.005 & 0.803 \\
\hline $\mathrm{NDF}(\% \mathrm{DM})^{2)}$ & $36.6^{\mathrm{a}}$ & $37.5^{\mathrm{a}}$ & $32.4^{\mathrm{b}}$ & $27.4^{\mathrm{c}}$ & 1.3 & $<0.001$ & 0.033 & 0.006 \\
\hline NFC (\% DM) ${ }^{2)}$ & $38.4^{\mathrm{a}}$ & $36.0^{\mathrm{a}}$ & $44.6^{\mathrm{b}}$ & $48.4^{\mathrm{b}}$ & 1.5 & $<0.001$ & 0.226 & $<0.001$ \\
\hline Soluble sugars (\% DM) & $5.4^{\mathrm{a}}$ & $0.9^{\mathrm{b}}$ & $6.0^{\mathrm{a}}$ & $2.3^{c}$ & 0.6 & 0.027 & $<0.001$ & 0.059 \\
\hline
\end{tabular}

1) TMR-D: TMR for dairy cattle; TMR-B: TMR for beef cattle; Respective TMRs manufactured on three different days were collected and analyzed; ${ }^{2)}$ NDF: Neutral detergent fiber; NFC: Non-fiber carbohydrates; ${ }^{a, b, c, d}$ Values with different letters in a row are significantly different $(\mathrm{p}<0.05)$.

Table 2: Results of in vitro rumen cultivation of the TMRs and the ensiled TMRs (eTMR)

\begin{tabular}{|c|c|c|c|c|c|c|c|c|}
\hline & \multicolumn{2}{|c|}{ TMR-D ${ }^{1)}$} & \multicolumn{2}{|c|}{ TMR-B') } & \multirow[t]{2}{*}{ SEM } & \multicolumn{2}{|c|}{ p-value } & \multirow[b]{2}{*}{$\begin{array}{l}\text { Type } \times \\
\text { Ensiling }\end{array}$} \\
\hline & $\begin{array}{l}\text { TMR } \\
(\mathrm{n}=3)\end{array}$ & $\begin{array}{l}\text { eTMR } \\
(\mathrm{n}=3)\end{array}$ & $\begin{array}{l}\text { TMR } \\
(\mathrm{n}=3)\end{array}$ & $\begin{array}{l}\text { eTMR } \\
(\mathrm{n}=3)\end{array}$ & & Type & Ensiling & \\
\hline Gas production $(\mathrm{mL})$ & 208 & 213 & 207 & 216 & 2 & 0.861 & 0.067 & 0.462 \\
\hline $\mathrm{CH}_{4}(\mathrm{~mL})$ & $16.3^{\mathrm{a}}$ & $19.1^{\mathrm{b}}$ & $13.0^{c}$ & $15.9^{\mathrm{a}}$ & 0.7 & $<0.001$ & $<0.001$ & 0.775 \\
\hline $\operatorname{DMD}(\%)^{2)}$ & $53.1^{\mathrm{a}}$ & $54.0^{\mathrm{a}}$ & $50.4^{\mathrm{b}}$ & $53.8^{\mathrm{a}}$ & 0.6 & 0.018 & 0.003 & 0.035 \\
\hline$m c r A\left(\times 10^{3}\right.$ copies $/ \mathrm{mL}$ culture $)$ & $894^{a}$ & $4167^{b}$ & $159^{c}$ & $875^{\mathrm{a}}$ & 497 & $<0.001$ & $<0.001$ & 0.011 \\
\hline Total short-chain fatty acids (SCFAs, mM) & $119^{\mathrm{ab}}$ & $124^{c}$ & $115^{\mathrm{a}}$ & $122^{\mathrm{bc}}$ & 1 & 0.022 & 0.002 & 0.178 \\
\hline Acetate (mol\% of total SCFAs) & $52.6^{\mathrm{a}}$ & $55.2^{\mathrm{b}}$ & $46.7^{\mathrm{c}}$ & $49.7^{\mathrm{d}}$ & 1.0 & $<0.001$ & $<0.001$ & 0.599 \\
\hline Propionate (mol\% of total SCFAs) & $31.8^{\mathrm{a}}$ & $30.1^{\mathrm{a}}$ & $35.7^{\mathrm{b}}$ & $35.5^{\mathrm{b}}$ & 0.7 & $<0.001$ & 0.091 & 0.108 \\
\hline Butyrate (mol\% of total SCFAs) & $15.6^{\mathrm{a}}$ & $14.7^{\mathrm{b}}$ & $17.6^{c}$ & $14.8^{\mathrm{ab}}$ & 0.4 & $<0.001$ & $<0.001$ & $<0.001$ \\
\hline
\end{tabular}

members of the rumen flora (e.g., Bacteroidetes and Firmicutes) (Dehority, 2003b), and anaerobic conversion into organic acids such as succinate, propionate, and butyrate, all of which are alternative $\mathrm{H}_{2}$ sink other than methane (Russell and Rychlik, 2001). Conversely, as carbohydrates in the TMR-Ds available for anaerobic digestion in the in vitro culture included more amount of fiber than in the case of the TMR-Bs, more fiber digestion by fiber-degrading bacteria may occur resulting in increased production of acetate accompanied with hydrogen, which was used for reduction of $\mathrm{CO}_{2}$ to methane generation (Dehority, 2003a). The observation that the amount of methane production was higher in the TMR-Ds than in the TMR-Bs may support this suggestion.

Moreover, we succeeded to determine the relative abun- dance of methanogenic archaea in respective cultures by quantifying a gene involved in the methane production $(m c r A)$ and found that the copy number of $m c r A$ was higher in the eTMRs than the TMRs. We also found that there was high correlation between methane production and $m c r A$ abundance $(\mathrm{Y}=1.87 \ln \mathrm{X}+3.55$ where $\mathrm{Y}$, methane production $[\mathrm{mL}]$ and $\mathrm{X}, m c r A$ abundance $\left[\times 10^{3}\right.$ copies $/ \mathrm{mL}$ culture]; $r=0.821)$ in the incubation experiment, suggesting that numerical increases in methanogen cells may be involved in the increase in amount of methane generation. The observation of higher $m c r A$ copy number determined in eTMR than in the original TMR suggests that ensiling TMR may originally confer some effects on the increase in methanogens. This suggestion may be related with a previous observation of high NDF digestibility in ensiled TMR when it was evaluated in an in vivo digestibility assessment 
(Cao et al., 2010a), which possibly links greater fiber digestion in the rumen. As described above, rumen methane production is generally higher when more fibrous feed is applied to cattle (Dehority, 2003a). A remarkable decrease in methane generation in response to ensiling TMR was reported in a previous in vitro study (Cao et al., 2012). In that case, it was assumed, providing relatively low DMD (approximately 30 to $40 \%$ of total), that NFC digestion may precede fiber digestion. Indeed, in the present experiment, the difference in mount of methane generated was not significant between the eTMRs and the TMRs when DMD was low in samples at six hours incubation (data not shown).

Taken together, as not only ensiling TMR but also the composition of TMR possibly affects rumen fermentation patterns, it could not be concluded that eTMR decreases methane generation in culture in vitro compared to the original TMR. In addition, we could determine the relative abundance of methanogen by monitoring $\operatorname{mcr} A$ to estimate the impact of the ensiling of TMR on the rumen methanogens. Our data suggest that eTMR may rather effect on the increase of the methanogens. On the other hand, the depression effect of eTMR on methane emission has been attributed to a generation of lactic acid during ensiling which has been suggested to be used to eliminate hydrogen on the synthesis of propionic acid in the rumen (Cao et al., 2010b). As these ideas are contrary to increasing or decreasing methane production, detailed monitoring of the digestion kinetics of nutrients, as well as of microbial interactions within the ecosystem may warrant to clarify the mechanism and to determine ways of practical use of eTMR as a feed to optimize rumen fermentation.

\section{CONFLICT OF INTEREST}

There exist no conflict of interest.

\section{AUTHORS' CONTRIBUTION}

Allthe authhors contributed equally.

\section{ACKNOWLEDGEMENTS}

A part of this study was financially supported by Grantsin-Aid for Scientific Research, Japan Society for the Promotion of Science (25450939).

\section{REFERENCES}

-Abrar A, Tsukahara T, Kondo M, Ban-Tokuda T, Wang C, Matsui $H$ (2015). Effect of monensin withdrawal on rumen fermentation, methanogenesis and microbial populations in cattle. Anim. Sci. J. in press. http://dx.doi.org/10.1111/

\section{asj.12368}

- Cao Y, Takahashi T, Horiguchi K, Yoshida N, Cai Y (2010a). Methane emissions from sheep fed fermented or nonfermented total mixed ration containing whole-crop rice and rice bran. Anim. Feed Sci. Technol. 157: 72-78. http:// dx.doi.org/10.1016/j.anifeedsci.2010.02.004

- Cao Y, Takahashi T, Horiguchi K, Yoshida N (2010b). Effect of adding lactic acid bacteria and molasses on fermentation quality and in vitro ruminal digestion of total mixed ration silage prepared with whole crop rice. Grassl. Sci. 56: 19-25. http://dx.doi.org/10.1111/j.1744-697X.2009.00168.x

- Cao Y, Takahashi T, Horiguchi K, Yoshida N, Zhou D (2012). In vitro ruminal dry matter digestibility and methane production of fermented total mixed ration containing whole-crop rice and rice bran. Grassl. Sci. 58: 133-139. http://dx.doi.org/10.1111/j.1744-697X.2012.00254.x

-Dehority BA (2003a). Cellurose digesting rumen bacteria. In: Dehority, BA (Ed.), Rumen Microbiology. Nottingham Univ. Press, Nottingham, UK, pp. 177-208.

-Dehority BA (2003b). Numbers, factors affecting the population and distribution of rumen bacteria. In: Dehority, BA (Ed.), Rumen Microbiology. Nottingham Univ.Press, Nottingham, UK, pp. 265-294.

-Denman SE, Tomkins NW, McSweeney CS (2007). Quantitation and diversity analysis of ruminal methanogenic populations in response to the antimethanogenic compound bromochloromethane. FEMS Microbiol. Ecol. 62: 313-322. http://dx.doi.org/10.1111/j.1574-6941.2007.00394.x

-Eckard RJ, Grainger C, de Klein CAM (2010). Options for the abatement of methane and nitrous oxide from ruminant production: A review. Livest. Sci. 130: 47-56. http://dx.doi. org/10.1016/j.livsci.2010.02.010

-Kondo M, Shimizu K, Jayanegara A, Mishima T, Matsui H, Karita S, Goto M, Fujihara T (2015). Changes in nutrient composition and in vitro ruminal fermentation of total mixed ration silage stored at different temperatures and periods. J. Sci. Food Agri. in press. http://dx.doi.org/10.1002/jsfa.7200

-Lima R, Lourenco M, Diaz R, Castro A, Fievez V (2010). Effect of combined ensiling of sorghum and soybean with or without molasses and lactobacilli on silage quality and in vitro rumen fermentation. Anim. Feed Sci. Technol. 155: 122131. http://dx.doi.org/10.1016/j.anifeedsci.2009.10.008

-Lwin K-O, Kondo M, Ban-Tokuda T, Lapitan RM, Del-Barrio AN, Fujihara T, Matsui H (2012). Ruminal fermentation and microbial ecology of buffaloes and cattle fed the same diet. Anim. Sci. J. 83: 767-776. http://dx.doi.org/10.1111/ j.1740-0929.2012.01031.x

-Morgavi D, Forano E, Martin C, Newbold C (2010). Microbial ecosystem and methanogenesis in ruminants. Animal. 4: 1024-1036.

-Nishino N, Wada H, Yoshida M, Shiota H (2004). Microbial counts, fermentation products, and aerobic stability of whole crop corn and a total mixed ration ensiled with and without inoculation of Lactobacillus casei or Lactobacillus buchneri. J. Dairy Sci. 87: 2563-2570. http://dx.doi.org/10.3168/jds. S0022-0302(04)73381-0

-Russell JB, RychlikJL (2001). Factors that alter rumen microbial ecology. Science. 292: 1119-1122.

-Wang F, Nishino N (2008). Ensiling of soybean curd residue and wet brewers grains with or without other feeds as a total mixed ration. J. Dairy Sci. 91: 2380-2387.

-Weinberg Z, Chen Y, Miron D, Raviv Y, Nahim E, Bloch A, Yosef E, Nikbahat M, Miron J (2011). Preservation of 
total mixed rations for dairy cows in bales wrapped with

Advances in Animal and Veterinary Sciences

polyethylene stretch film-A commercial scale experiment.

Anim. Feed Sci. Technol. 164: 125-129.

April 2016 | Volume 4 | Issue 4 | Page 182 